\title{
A quadratic approach to allometry yields promising results for the study of growth
}

\author{
Etienne Geraert
}

Department of Biology, Ledeganckstraat 35, University Gent, Belgium, e-mail: etienne.geraert@UGent.be

\begin{abstract}
Julian HUXLEY (1924) came to the conclusion that intra-specific growth usually follows a sequence of power curves. So HuXLEY claimed that during growth sudden changes in the growth rate can occur. The restudy of his material, however, reveals that his observations closely follow single quadratic curves. As a result the intra-specific allometry studied by HUXLEY is comparable to ontogenetic allometry. The quadratic factor of the quadratic equations obtained, represents the growth rate; it shows the constant increase (positive factor) or decrease (minus factor) of one of the measurements for a constant increase in the other measurement with which it is compared. The quadratic factor explains the entire growth process and is the same for the smaller (younger) and larger (older) specimens. It could probably permit the prediction of the shape of larger and/or smaller animals not yet found, or give a clue to some evolutionary changes. By using the quadratic parabola there is no need to postulate "sudden changes in the growth curve" and so it appears that HUXLEY's power curve can be abandoned.
\end{abstract}

KEY words: allometry, Huxley, parabolic curve, quadratic equation, shore crab, stag beetle.

\section{INTRODUCTION}

HUXLEY's (1924) assumption was, when he compared the measurements of body part $y$ with body part $\mathrm{x}$, that for a theoretical, small amount of growth, there is a constant ratio between the two growth rates

$$
\mathrm{dy} / \mathrm{dx}=\text { constant } \mathrm{k}(1)
$$

This resulted in the formula of allometric growth:

$$
y=b x^{k}
$$

"b" and " $k$ " being constant factors. This exponential formula can also be written as:

$$
\log \mathrm{y}=\log \mathrm{b}+\mathrm{k} \log \mathrm{x}(3)
$$

As a result the curvilinear relationship (2) is linearized when the data are plotted onto a log$\log$ scale; the slope of that line is represented by the power factor " $k$ " (known as the allometric coefficient) and $\log b$ is the intercept of the line on the y-axis.

The study of growth has been, thereafter, greatly influenced by Huxley's proposal, although doubts have also been expressed. The results on log-log graph paper often show not a single straight line, but two-three consecutive straight lines. These observations have been explained by proposing "sudden changes" in the allometric constant $\mathrm{k}$. These "sudden changes" have cast some doubt on the allometric formula and several other formulas have been proposed (a review is found in ZEGER \& HARLOW, 1987). Recent publications on that matter are e.g. STERN \& EMLEN (1999); GAYON (2000); KNELL et al. (2004); SHINGLETON (2010) and PACKARD (2012).

The term allometry was introduced by HUXLEY \& TEISSIER (1936). It designates the changes in relative dimensions of parts of an organism that are correlated with changes in shape and overall size (LEVINTON, 1988 in GAYON, 2000).

PACKARD (2012) restudied HUXLEY's measurements of Uca pugnax (SMITH, 1870) and presented not only a two-parameter power function but also a three-parameter power function; this three-parameter model "is better than the two-parameter model for describing 
the observations". In a remark on that article, GERAERT (2013) suggested that a quadratic parabolic curve is as good as or even better than a power function to explain the observations.

GERAERT (2004), studying ontogenetic allometry, has shown that there is a constant change in the relationship (and not a constant relationship) between a small amount of growth of body part y compared to that of body part $\mathrm{x}$; mathematically speaking, "the second difference" is constant. That second difference is the growth rate and is present in the quadratic factor of a quadratic equation; the other factors in that equation have no biological meaning but are necessary to position the quadratic curve in a diagram.

GERAERT (2004) followed growth data from the new-born stage to the adult. HUXLEY (1924, 1932) based his assumptions mainly on the variation found in adults, not only on the males of the fiddler crab, but also on the males and females of the shore crab (Carcinus maenas) and on male mandibles in three species of stag-beetles (Lucanidae). The very large variation observed in these adults was interpreted by HUXLEY (1924, 1932) also as "growth". In this study, an attempt is made to see if a quadratic parabola can also be used to describe variation in adults, called "comparative" growth in GERAERT (2013), and "static" and "intra-specific" allometry in GOULD (1966) and GAYON (2000).

\section{RESULTS}

\section{Carcinus maenas L. (Fig. 1)}

HUXLEY \& RICHARDS (1931) studied the increase of width of the abdomen in comparison with the increase of carapace length; the measurements were split into three categories: "unsexables", females and males. HuXLEY

\section{Carcinus maenas}

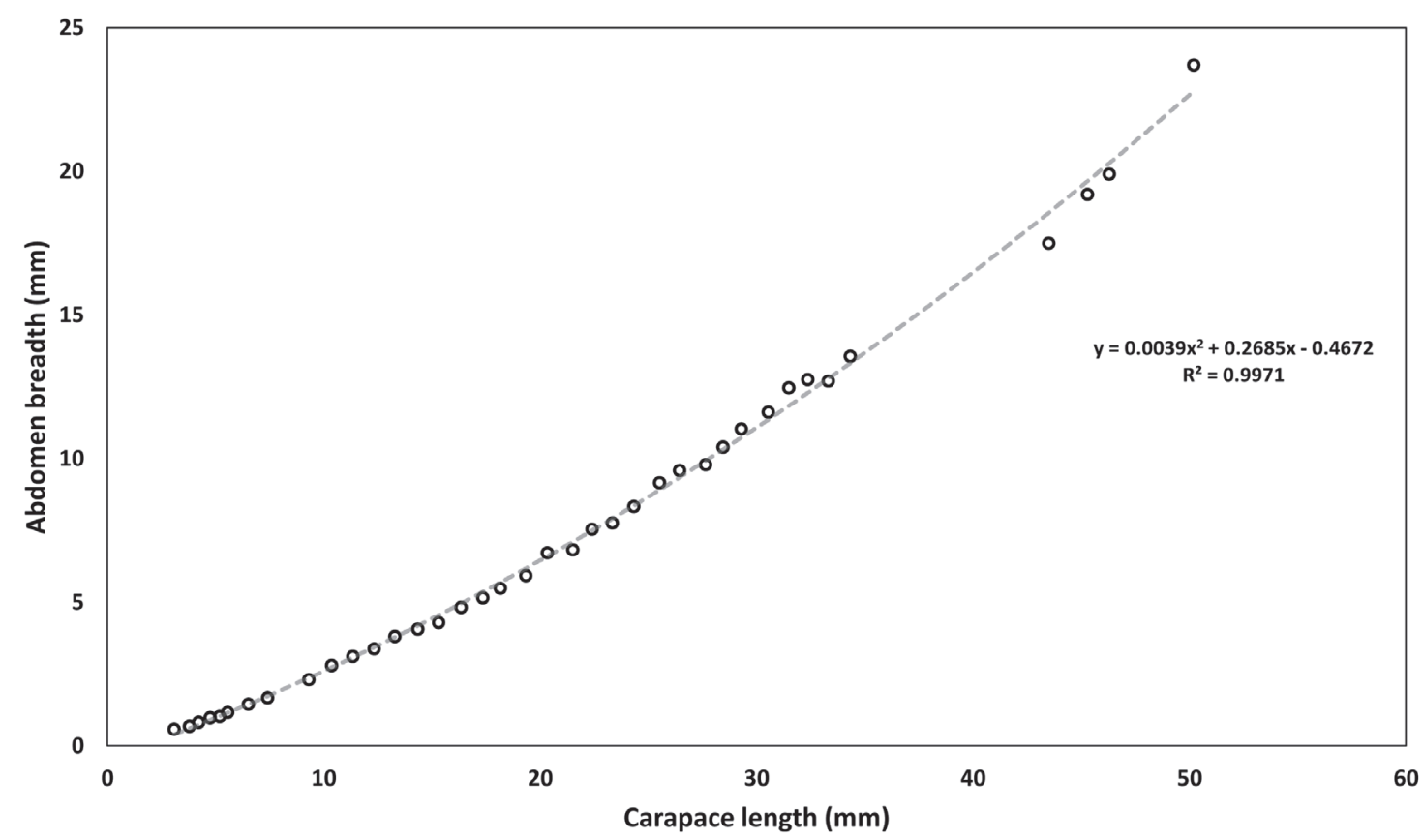

Fig. 1. - Comparison of carapace length to abdomen breadth in Carcinus maenas. The measurements given in HUXLEY (1932) are represented on a double arithmetic scale (and not on a log-log scale); the open circles are the measurements for the unsexed specimens and for the adult females of the shore crab. The calculated quadratic parabola is added. 
(1932) gave the measurements for the unsexables and for the females; he used "abdomen-breadth" as Y and "carapace-length" as X (both in $\mathrm{mm}$ ). The quadratic equation linking both is:

$\mathrm{Y}=0.0039 \mathrm{X}^{2}+0.2685 \mathrm{X}-0.467\left(\mathrm{R}^{2}=0.997\right)$

Per $10 \mathrm{~mm}$ increase in carapace length the abdomen breadth shows a constant secondary increase of $0.78 \mathrm{~mm}$ (this is twice the quadratic factor). The differences between the observed Y-values and the calculated Y-values are small for whatever $\mathrm{X}$-value is considered (Table 1).

$\sum(\mathrm{Y} \text { calculated }-\mathrm{Y} \text { observed })^{2}=3.7 \mathrm{~mm}^{2}$

The mean difference between $\mathrm{Y}$ calculated and $\mathrm{Y}$ observed is approximately $0.1 \mathrm{~mm}$; this difference varies from zero to $0.9 \mathrm{~mm}$.

\section{Cyclommatus tarandus (THUNBERG, 1806)}

(Fig. 2)

HUXLEY $(1927,1932)$ studied the increase of the mandibles in several species of the Lucanidae, the stag beetles; he used the measurements of DUDICH (1923) for Cyclommatus tarandus. In this case $\mathrm{Y}=$ mandible length in $\mathrm{mm}$ and $\mathrm{X}=$ body length + mandible length also in $\mathrm{mm}$. The quadratic equation linking both is:

$$
\mathrm{Y}=-0.0011 \mathrm{X}^{2}+0.71 \mathrm{X}-11.41\left(\mathrm{R}^{2}=0.997\right)
$$

Per $10 \mathrm{~mm}$ increase in the total length $\mathrm{X}$ there is a constant secondary decrease of $0.22 \mathrm{~mm}$ in the mandible length (this is twice the quadratic factor); this small quadratic factor indicates that an almost straight line is observed (This may be largely due to the fact that measurement $\mathrm{Y}$ is included in $\mathrm{X}$ ). The differences between the observed Y-values and the calculated Y-values are small for whatever $\mathrm{X}$-value is considered (Table 1).

$$
\sum(\mathrm{Y} \text { calculated }-\mathrm{Y} \text { observed })^{2}=5.35 \mathrm{~mm}^{2}
$$

The mean difference between $\mathrm{Y}$ calculated and $\mathrm{Y}$ measured is approximately $0.44 \mathrm{~mm}$; this difference varies from zero to $1.3 \mathrm{~mm}$.

\section{Cyclommatus tarandus}

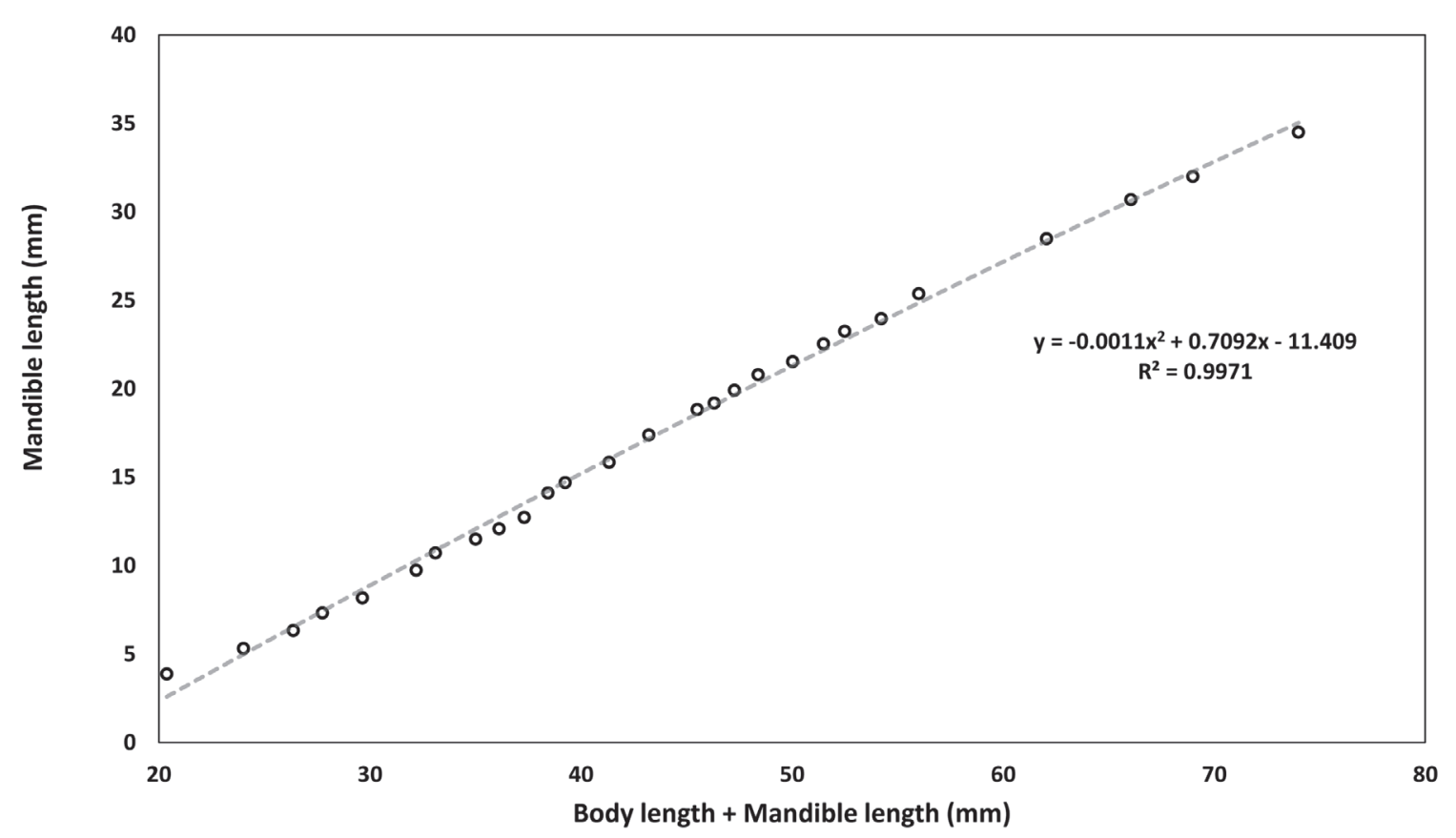

Fig. 2. - Comparison of total length (= body length + mandible length) to mandible length in Cyclommatus tarandus. The measurements given in HUXLEY (1932) are represented on a double arithmetic scale (and not on a log-log scale); the open circles are the measurements for the males of this stag beetle. The calculated quadratic parabola is added. 


\section{TABLE 1}

Calculated values for Carcinus maenas and Cyclommatus tarandus based on the measurements given in HUXLEY (1932). The calculated values are obtained by using the quadratic equation shown in the text; the Y-values are calculated by a constant increase of the X-values with $10 \mathrm{~mm}$. As a result the constant second differences in the $\mathrm{Y}$-values are obtained. $\mathrm{X}$ and $\mathrm{Y}$ are explained in the text.

\begin{tabular}{c|c|c|c|c|c|c|c|}
\multicolumn{4}{|c|}{ CARCINUS MAENAS } & \multicolumn{4}{c}{ CYCLOMMATUS TARANDUS } \\
$\begin{array}{c}\text { X-value } \\
\text { in mm }\end{array}$ & $\begin{array}{c}\text { Y-value } \\
\text { calculated }\end{array}$ & $\begin{array}{c}\text { Increase } \\
\text { in } \\
\text { Y-values }\end{array}$ & $\begin{array}{c}\text { Second } \\
\text { difference }\end{array}$ & $\begin{array}{c}\text { X-value } \\
\text { in mm }\end{array}$ & $\begin{array}{c}\text { Y-value } \\
\text { calculated }\end{array}$ & $\begin{array}{c}\text { Increase } \\
\text { in } \\
\text { Y-values }\end{array}$ & $\begin{array}{c}\text { Second } \\
\text { differences }\end{array}$ \\
10 & 2.606 & 3.850 & & 20 & 2.336 & 6.543 & \\
20 & 6.456 & 4.627 & 0.78 & 30 & 8.879 & 6.322 & -0.22 \\
30 & 11.083 & 5.403 & 0.78 & 40 & 15.201 & 6.102 & -0.22 \\
40 & 16.487 & 6.180 & 0.78 & 50 & 21.303 & 5.882 & -0.22 \\
50 & 22.667 & & 60 & 27.186 & &
\end{tabular}

\section{DISCUSSION}

The allometric equation (2) (3) needs two factors ("b" and " $k$ ") to describe the relationship between the measurements $\mathrm{X}$ and $\mathrm{Y}$. The meaning of each one of them has been a debate during many years and is summarized in GAYON (2000); no final conclusion is reached. The quadratic equation has only one factor that shows the constant increase (positive factor) or decrease (minus factor) of one of the measurements for a constant increase in the other measurement with which it is compared.

HUXLEY (1932) did not find the single straight line (3) needed to support his theory in the two cases restudied here (and in the fiddler crab restudied in GERAERT, 2013). For the shore crab the logarithmic plotting showed a kink in the observations as well for females as for males, so a different growth coefficient was observed for young females (males) and older females (males). HuXLEY (1932) gave several k-values (added on Fig. 3) that he experimentally derived from his figure, moreover the constant "b" has not been given. Therefore it is not possible to compare his (several) equations with the single quadratic equation obtained. The straight lines found by HUXLEY (1932) in his log-log diagram
(Fig. 3) can be interpreted as mathematical accidents; on the other hand in Fig. 1 one can suggest another three consecutive straight lines: these are mathematical accidents as well in this arithmetic diagram.

For the stag beetles HuXLEY (1932) found that all curves inflect at large absolute sizes; for the smaller animals of Cyclommatus tarandus he gave a k-value of 1.97 and a b-value of "just over 0.01 ". (Fig. 4). So, it is not relevant to compare his curve restricted to the smaller animals with the quadratic one presented here, that includes all the measurements.

Nevertheless HUXLEY continued propagating the power curve for describing growth. His proposal has been generally accepted, as for example in recent times by KNELL et al. (2004) for the stag beetle; SHINGLETON (2010) for the fiddler crab. On the other hand the quadratic curve closely follows all the observations including those relating to the smallest and the largest animals; the single quadratic factor explains the entire process.

CHAMPY (1924), cited by GAYON (2000), argued that the relative growth process was adequately described by a parabolic curve of 
the shape $\mathrm{V}=a t^{2}$; this curve is a special case of a power curve and is different from the curve proposed here. TEISSIER (1931), cited by GAYON (2000), observed that CHAMPY's law was indeed a good approximation for some insects. MARTIN (1960), KidWELL \& HOWARD (1970) and WALKER \& KOWALSKI (1971) using curve-fitting programs observed that a parabolic curve gave the best approximation for their measurements on growth; every one of these authors stressed that this discovery was arbitrary and had no biological meaning. Apparently no one thereafter used or mentioned the quadratic equation (ZEGER \& HARLOW, 1987).

\section{CONCLUSIONS}

1. The quadratic equation explaining ontogenetic allometry (GERAERT, 2004) explains (in the cases studied) intra-specific allometry as well.

2. HuXLEY's (1924) proposal to use a power curve to explain intraspecific allometry seems no longer acceptable. By using the quadratic curve there is no need for such explanations as "sudden changes in the growth factor" or "the curve inflects at large absolute size"; there is one and only one factor that describes relative growth and that is the quadratic factor of the quadratic equation.

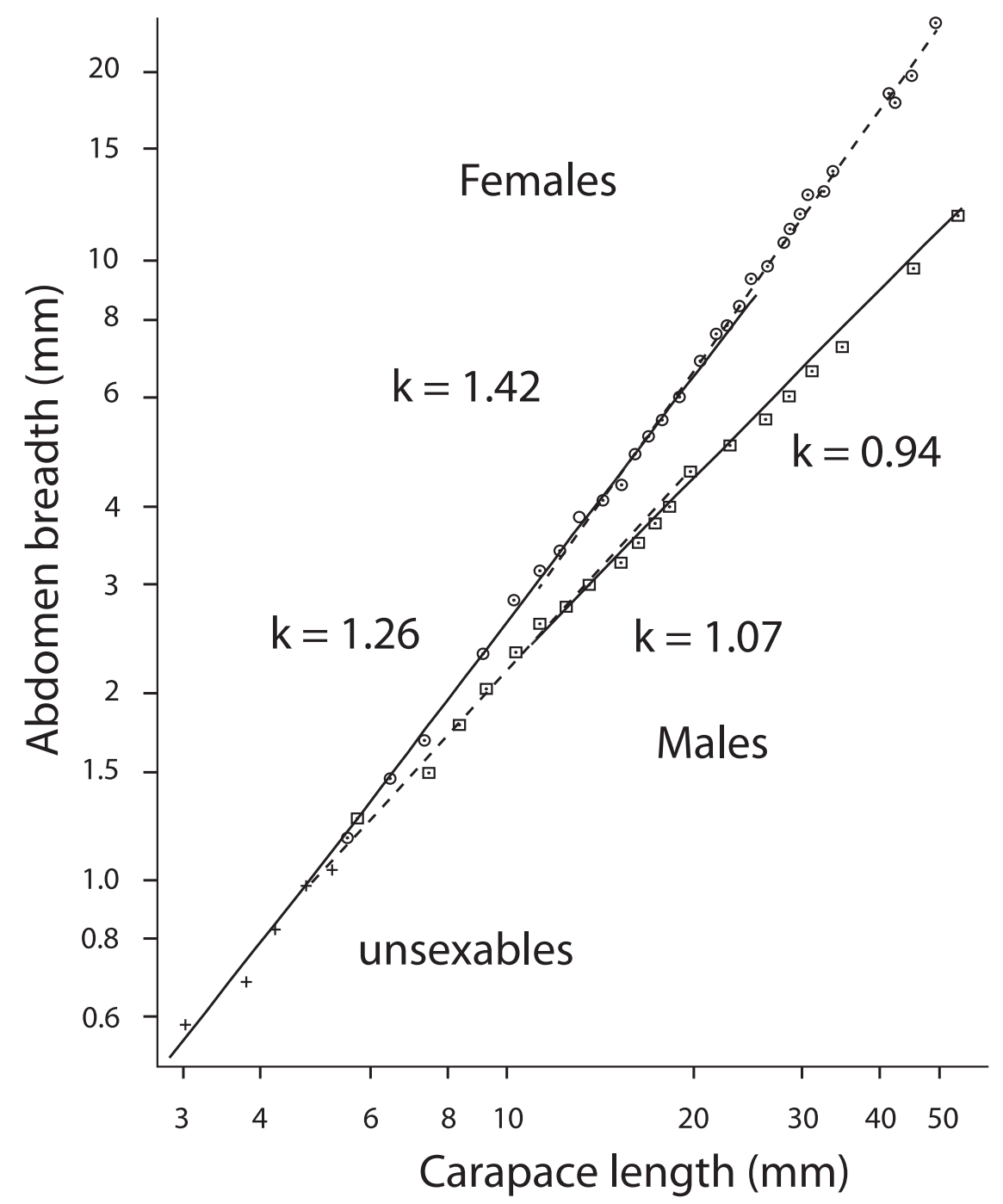

Fig. 3. - Figure taken from HUXLEY (1932) with the following explanation: "Increase of width of abdomen with increase of carapace length in the shore crab, Carcinus maenas: logarithmic plotting". The signs for unsexables, males and females are explained on the graph; the growth coefficients given by HUXLEY (1932) were also added. 


\section{Presumptions}

3. The use of a quadratic equation in a case of intra-specific allometry could allow prediction of the shape of larger and/or smaller specimens not yet observed.

4. It can be assumed that changes in the growth factor(s) do now-and-then occur and have occurred in the past; such shifts could perhaps explain some evolutionary changes.

\section{REFERENCES}

Champy C (1924). Sexualité et hormones. Doin, Paris.

Dudich E (1923). Über die Variation des Cyclommatus tarandus Thunberg (Coleoptera, Luca- nidae). Archiv für Naturgeschichte 89 (1-4): 6296.

GAYON J (2000). History of the concept of allometry. American Zoologist, 40: 748-758.

GERAERT E (2004). Constant and continuous growth reduction as a possible cause of ageing. International Journal of Developmental Biology, 48: $271-274$.

GERAERT E (2013). Remarks on the article of Packard (2012) "Julian Huxley, Uca pugnax and the allometric method". Journal of Experimental Biology, 216 (3): 535.

GouLD SJ (1966). Allometry and size in ontogeny and phylogeny. Biological Reviews of the Cambridge Philosophical Society, 41: 587-640.

HuXLEY JS (1924). Constant differential growthratios and their significance. Nature, 114: 895896.

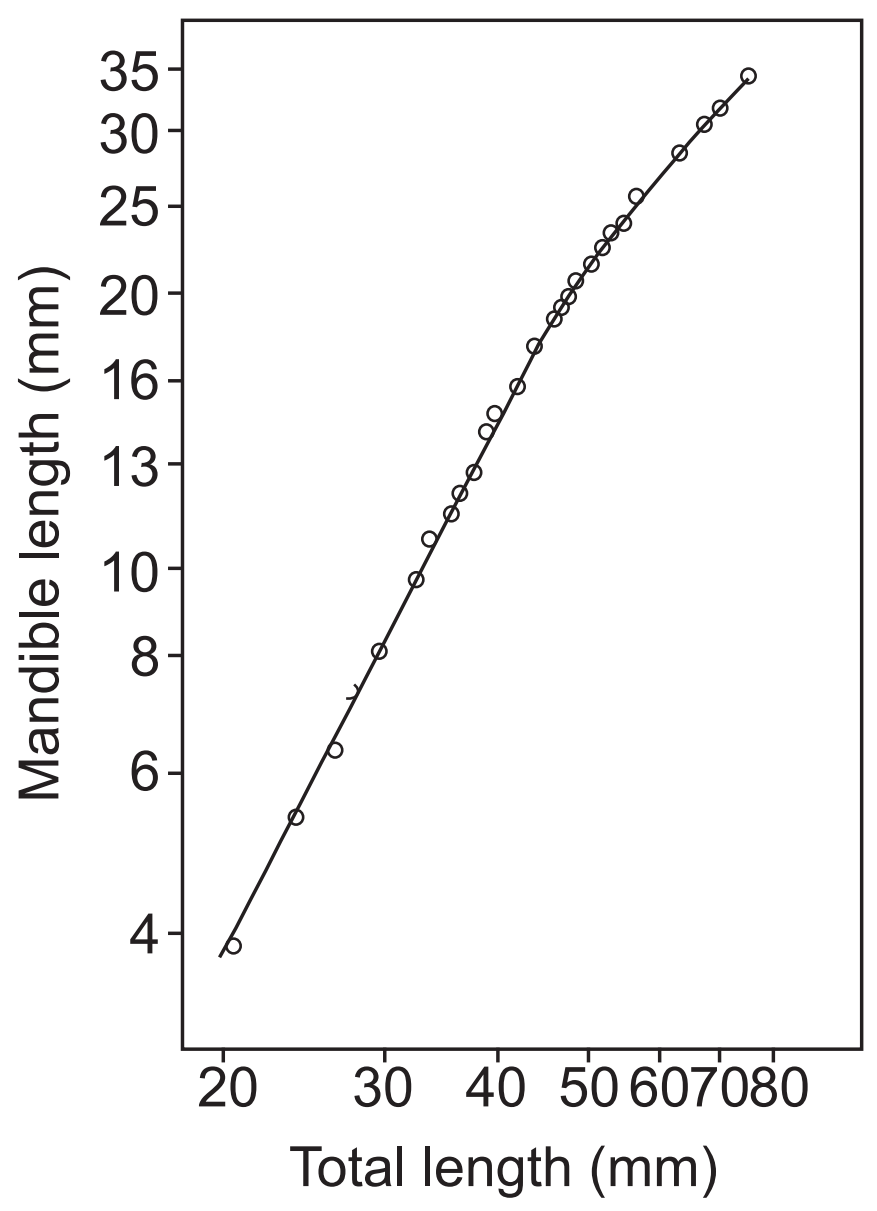

Fig. 4. - Figure taken from HUXLEY (1932) with the following explanation: "Relative growth of male mandibles in three species of stag-beetles (Lucanidae)". The results for Lucanus cervus and L. lunifer were, however, omitted. The explanation for Cyclommatus tarandus reads as follows: "Total length is true total length (= body length + mandible length). The curve inflects at large absolute size; for the remainder of the curve $\mathrm{k}$ is about $2.0 "$. 
HuXLeY JS (1932). Problems of Relative Growth. Methuen \& Co, London.

HUXLEY JS \& TEISSIER G (1936). Terminology of relative growth. Nature, 137: 780-781.

KIDWELL JF \& HowARD A (1970). The inheritance of growth and form in the mouse. III. Orthogonial polynomials. Growth, 34: 87-97.

KNELl RJ, POMFRET JC \& TOMKINS JL (2004). The limits of elaboration: curved allometries reveal the constraints on mandible size in stag beetles. Proceedings of the Royal Society of London. Series B. Biological Sciences, 271: 523-528.

LEVINTON J (1988). Genetics, paleontology and macroevolution. Cambridge University Press, Cambridge.

MARTIN L (1960). Homométrie, allométrie et cograduation en biométrie générale. Biometrische Zeitschrift, 2: 73-97.

PACKARD GC (2012). Julian Huxley, Uca pugnax and the allometric method. Journal of Experimental Biology, 215: 569-573.

SHINGLETON A (2010). Allometry: The Study of Biological Scaling. Nature Education Knowledge 1 (9), 2.

SMITH SI (1870). Notes on American Crustacea. Number I. Ocypodoidea. Transactions of the Connecticut Academy of Arts and Science 2: 113176. Plates 2-4.
STERN DL \& EMLEN DJ (1999). The Developmental Basis for Allometry in Insects. Development, 126: 1091-1101.

TEISSIER G (1931). Recherches morphologiques et physiologiques sur la croissance des insects. Travaux de la Station Biologique de Roscoff, 9: 29-238.

ThunBerg P (1806). Lucani Monographia, elaborata. Mémoires de la Sociéte Imperiale des Naturalistes de Moscou, 1: 183-206, 1 pl.

WALKER GF \& KOWALSKI CJ (1971). A twodimensional coordinate model for the quantification, description, analysis, prediction and simulation of craniofacial growth. Growth, 35: 191-211.

ZEGER SL \& HARLOW SD (1987). Mathematical model from laws of growth to tools for biological analysis: fifty years of Growth. Growth, 51: 1-21.

Received: February 6th, 2015

Accepted: December 9th, 2015

Branch editor: Dominique Adriaens 